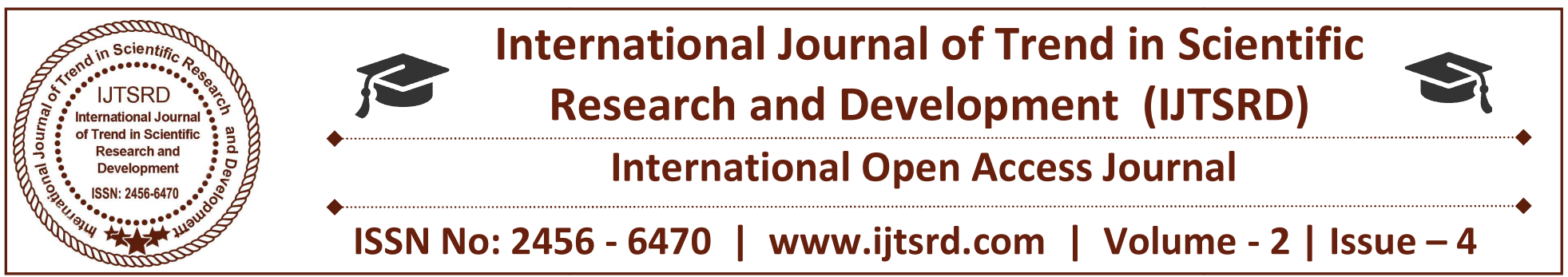

\title{
Performance Improvement Analysis and Simulation of Solar PV/T Water Collector
}

\author{
Amarnath. $K^{1}$, Dr. Gopal. $\mathbf{P}^{1}$, Sridharan. $\mathbf{M}^{1}$, Dr. T. Senthil Kumar ${ }^{2}$ \\ ${ }^{1}$ Department of Mechanical Engineering, University College of Engineering, \\ ${ }^{1}$ BIT Campus, Tiruchirappalii, Tamil Nadu, India \\ ${ }^{2}$ Dean, University College of Engineering, BIT Campus, Anna University, Trichy, Tamil Nadu, India
}

\section{ABSTRACT}

The objective of this paper is to review the collection of literature available on the Photo Voltaic and Thermal Solar Collector. The review paper is presented to show the comparison of findings obtained by various research works. In solar collector, the solar energy from the sun is converted in to electrical energy by means of Photo Voltaic panel and thermal energy by converting cold water into hot water. Nowadays, solar collector is preferred in many industries and house hold applications to reduce the demand of electricity by increasing the effective utilization of solar energy coming from the sun. The selection of collector design plays vital role in the development of heat energy and electrical energy. The input process parameters such as type of collector, time, mass flow rate, flow direction, flow pattern and size of the flow tube are normally considered for the research work and the output responses like thermal efficiency and electrical efficiency are appraised by using the Photo Voltaic Thermal Hybrid Solar Collector. Normally experiments are to be conducted based on the recommendation by the Traditional and Non-Traditional techniques. The output efficiency of the solar collector is purely based on the selection of input process parameters. Based on the literature review, an investigation is essential to improve the performance of the solar collector. The authors found that input process parameters plays vital role in the quality and efficiency of the solar collector.

Keywords: Solar Collector, Input process parameters, Output responses, Optimization techniques

\section{INTRODUCTION}

Photovoltaic thermal hybrid solar collectors, sometimes known as hybrid $\mathrm{PV} / \mathrm{T}$ systems or PVT, are systems that convert solar radiation into thermal and electrical energy. These systems combine a solar cell, which converts sunlight into electricity, with a solar thermal collector, which captures the remaining energy and removes waste heat from the PV module and thus be more overall energy efficient than solar photovoltaic (PV) or solar thermal alone.[1] A significant amount of research has gone into developing PVT technology since the 1970s.[2] Photovoltaic cells suffer from a drop in efficiency with the rise in temperature due to increased resistance. Such systems can be engineered to carry heat away from the PV cells thereby cooling the cells and thus improving their efficiency by lowering resistance.

\section{PV/T collector types}

$\mathrm{PV} / \mathrm{T}$ collectors can be flat plate or concentrating and are classified according to the type of the working fluid used water or air).

\subsection{Flat plate $P V / T$ collectors}

Flat plate PV/T collectors look very similar to the well-known flat plate thermal collectors. The only significant difference, as shown by the schematic of Fig. 1, is the PV panel which is attached on the top of the metallic absorber plate. The absorber plate with 
the tubes, the PV module, the glass cover as well as the insulation.

\subsection{Concentrating PV/T collectors:}

PV cost is relatively high, concentrators are often used to increase the irradiance level on PV modules. A low concentrating water cooled type $\mathrm{PV} / \mathrm{T}$ collector of the building integrated type, was recently investigated by Brogren et al. [2]. It incorporates $\mathrm{PV} / \mathrm{T}$ string modules with low cost aluminum foil reflectors with a concentration ratio of 4.3 times. Coventry [3] developed the so called CHAPS (combined heat and power solar) PV/T collector.

It involves a parabolic trough of concentration ratio of 37 times with mono crystalline silicon cells and a two-axis tracking system At the back of the cells a tube with water and anti-freeze was attached to collect most of the generated heat produced. various engineering systems including electronic components.

Heat pipe has ability to dissipate huge amount of heat with small temperature drop along the heat pipe while providing a self-pumping capable through a porous material in its structure. A limiting factor for the heat transfer potential of a heat pipe is depends working fluid properties.

The thermo physical properties of the fluid can be improved. An innovative way to enhance liquid thermal conductivity is the dispersion of highly conductive solid nanoparticles within the base fluid. Copper heat pipe and stainless steel heat pipe as shown in figure (a)

(a) 车

(c)

(c) 羿

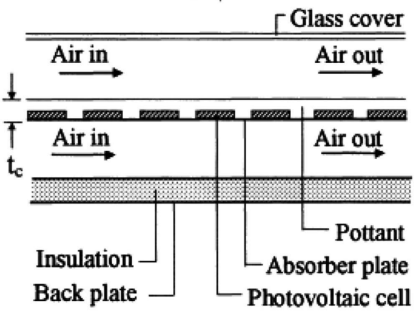

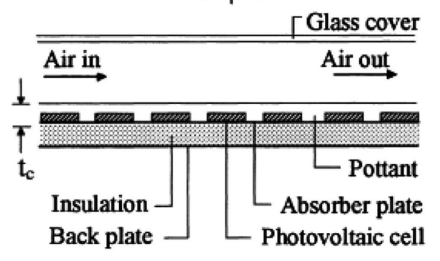

(b)

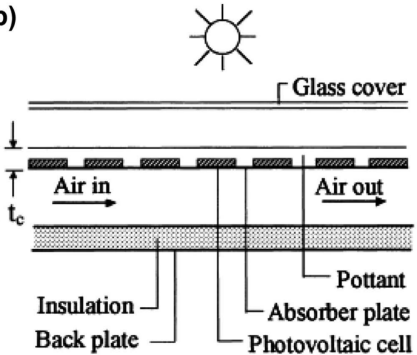

(d)

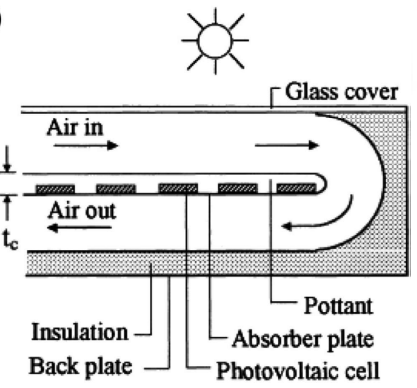

Figure 2.1 PV/T CROSS SECTION

Traveling through the adiabatic section the vapor reaches the condenser region where condensation rejects the latent heat of the fluid to the sink. The condensed liquid is pumped back against an adverse pressure gradient to the evaporator by a combination of the capillary pumping action and/or bulk forces.

This fluid circuit is repeated during the normal operation of the heat pipe and can continue as long as there is sufficient vapor pressure and capillary pressure to support its operation. Simple heat pipe as shown Figure 2.1.At the evaporator end the liquid recedes into the wick pores and hence the menisci in the pores at the vapor interface are highly curved. Whereas the liquid menisci at vapor interface in the condenser end are almost flat. This difference in the interface curvature of the menisci at the vapor interface coupled with the surface tension of the working fluid causes a capillary pressure gradient at the liquid-vapor interface along the length of the pipe. This capillary pressure gradient pumps the working fluid against various pressure losses such as friction, inertia and against bulk body forces. This axial variation of pressure is illustrated in Figure 2.

\subsection{Parametric studies of PV/T}

Packing factor one of the important parameters in designing and studying a PV/T system is packing factor, which generally means the fraction of absorber plate area covered by the solar cells. In specific applications such as buildings, Vats et al. [27] studied 
the effects of packing factor on energy and performed energy analysis of a PV/T system with air duct flow. Fig. 4 demonstrates the efficiency behaviors of different PV cell materials due to change in packing factor. For example, Fig. 1a shows the thermal and electrical annual energy variations caused by changing of packing factor in each PV cell modules.

The overall annual thermal energy and energy variations are shown in Fig. $1 \mathrm{~b}$ and $\mathrm{c}$ respectively at two different packing factors in each PV cells. The increase of packing factor doesn't always increase the annual energy gain or electrical efficiency. In the figure above, the effect of higher packing factor on the annual thermal efficiency and annual exergy analysis is also shown. If the packing factor is raised too much the thermal exit temperature will get higher due to absorbing high amount of thermal energy so it will increase the cell temperature, which causes the decrease in electrical efficiency. Meanwhile decreasing the packing factor too much will decrease the electrical efficiency because the radiation absorber area is less.

In the study of $\mathrm{Wu}$ et al. [25] on PV/T hybrid system, the energy analysis showed that the energy efficiency behaves quite irregularly .For example, according to the Fig. 2, the lower energy efficiency happens in packing factor equal to 0.8 in the experiment when they had three packing factors as $0.7,0.8$ and 0.9 . The higher energy efficiency is related to the packing factor equals to 0.9.In Fig. 5, we show the packing factors that different researchers have been used. It is obvious that most of the researchers chose the packing factors higher than $50 \%$ and less than $90 \%$. Generally speaking, a comprehensive knowledge about the variation of packing factor and its effects with different fluids in different PV/T systems still does not exist. This also opened the door for optimization of the system design.

\section{Experimental setup}

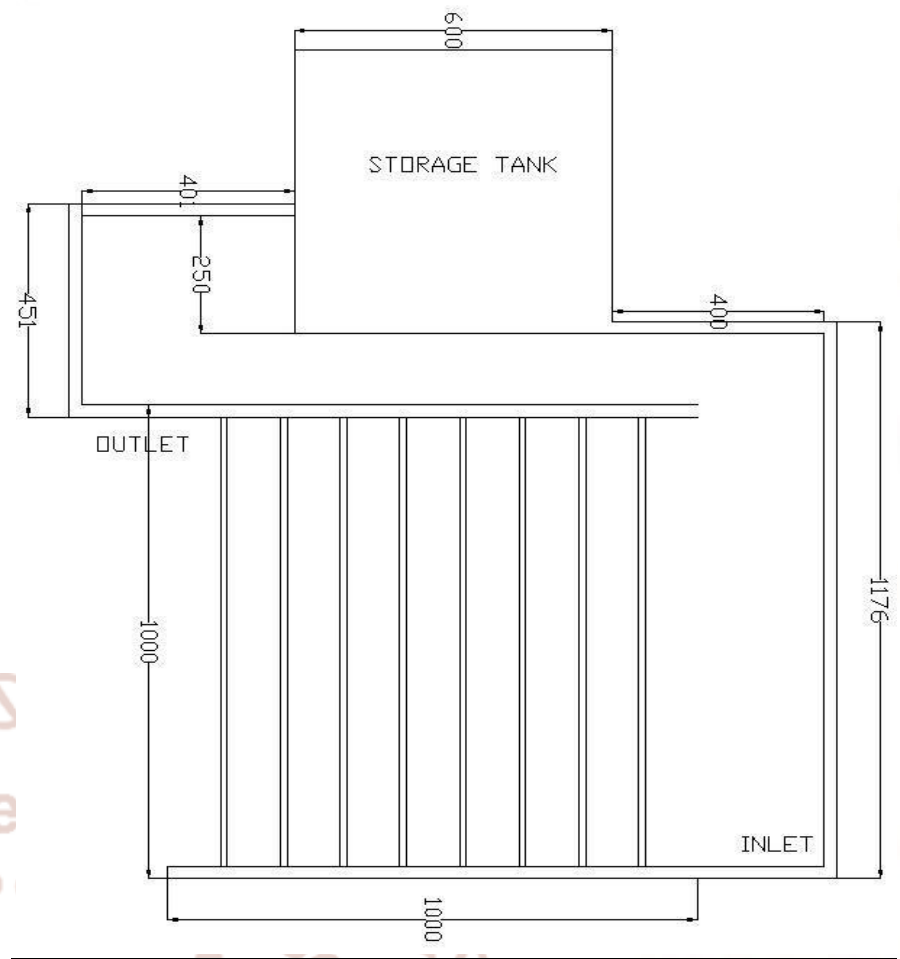

3.1.1 Schematic diagram of a PV/T system

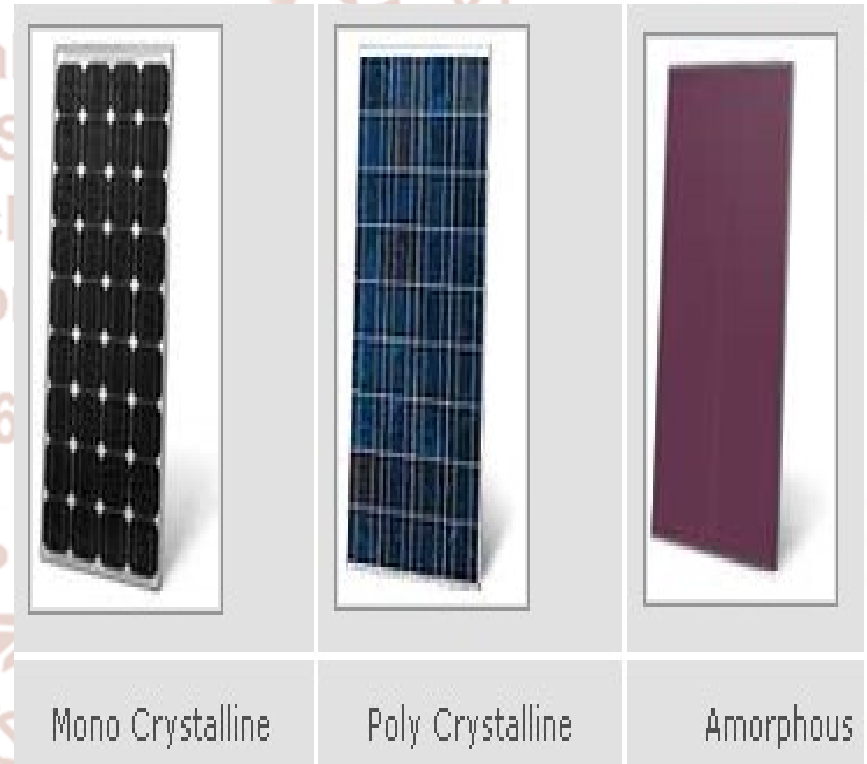

Fig: 3.1.2 PV Module

\subsection{PHOTOVOLTAICS:}

Photovoltaic (PV) is a method of generating electrical power by converting sunlight into direct current electricity using semiconducting materials that exhibit the photovoltaic effect. A photovoltaic system employs solar panels composed of a number of solar cells (PV cells) to supply usable solar power. The photovoltaic cell is the basic building block of a PV system. Individual cells can vary in sizes from about $1 \mathrm{~cm}$ to about $10 \mathrm{~cm}$ across. Most cells are made 
International Journal of Trend in Scientific Research and Development (IJTSRD) ISSN: 2456-6470

with silicon today. Silicon must be purified. This is one of the biggest expenses in the production of solar cells.

Cross section of a P.V. cell $\quad(P)=$ Photons $\quad(E)=$ Electrons

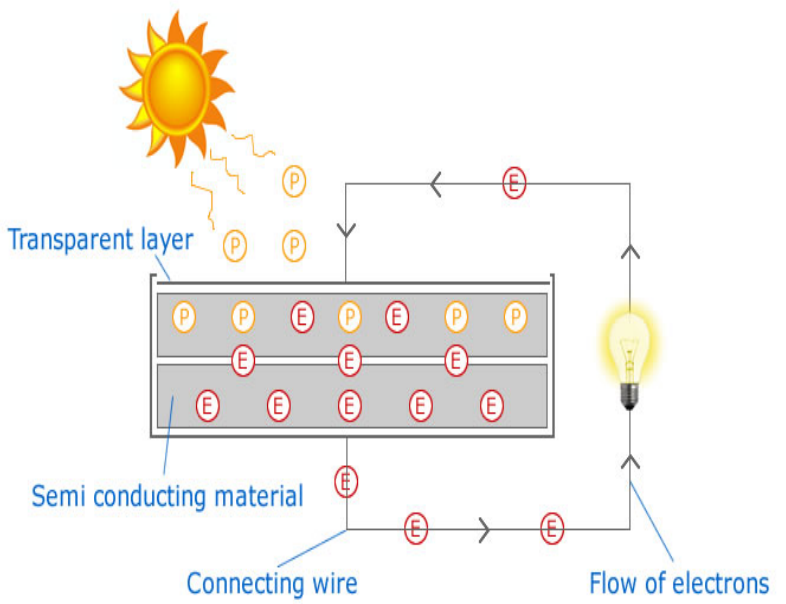

Figure 3.2.1: working principle of PV cell
$\mathrm{T}_{\mathrm{i}}=$ inlet fluid temperature

$\mathrm{T}_{\mathrm{a}}=$ ambient temperature

The collector heat removal factor may be calculated from the following equation:

$$
\mathrm{F}_{\mathrm{R}}=\frac{\dot{\mathrm{m}} \mathrm{C}_{\mathrm{p}}}{\mathrm{U}_{\mathrm{L}} \mathrm{A}_{\mathrm{c}}}\left(1-\exp \left[-\frac{\mathrm{U}_{\mathrm{L}} \mathrm{A}_{\mathrm{c}} \mathrm{F}_{\mathrm{p}}}{\dot{\mathrm{m} \mathrm{C}_{\mathrm{p}}}}\right]\right)
$$

$\dot{\mathrm{m}}=$ mass flow rate of the fluid

$\mathrm{C}_{\mathrm{p}}=$ heat capacity of fluid

The plate efficiency factor Fpis defined as

The plate efficiency factor $(\mathrm{Fp})$ for a tube in plate type of collector may be calculated from the following equation:

$$
F_{p}=\frac{1 / U_{L}}{W\left[\frac{1}{\pi D h_{f i}}+\frac{m_{t}}{\pi D K_{t}}+\frac{1}{C_{b}}+\frac{1}{U_{L}[D+(W-D) F]}\right]}
$$

\section{EFFICENCY CALCULATION}

\subsection{EFFICIENCY OF FLAT T PLATE}

\section{COLLECTORS:}

Where

The solar collector efficiency $\eta$ is defined as:

$W=$ center to center tube spacing

$$
\eta=\frac{\text { actual useful energy collected }}{\text { solar energy incident on the collector }}
$$

$$
\eta=\frac{Q_{u}}{I_{T} A_{C}}
$$

Where,

$\mathrm{Q}_{\mathrm{u}}=$ rate of useful heat collected from the collector

$\mathrm{I}_{\mathrm{T}}=$ total solar radiation incident on the collector per unit area and time

$\mathrm{A}_{\mathrm{C}}=$ aperture area of the absorber

Thus instantaneous efficiency of the flat plate collector is given as:

$$
\eta=F_{R}(\tau \alpha)_{e}-F_{R} U_{L} \frac{\left(T_{i}-T_{a}\right)}{I_{T}}
$$

$\pi=$ transmittance of the cover plates

$\alpha=$ absorptance of the black absorber surface
$\mathrm{D}=$ outside diameter of the tube

$\mathrm{h}_{\mathrm{fi}}=$ tube to fluid (film) heat transfer coefficient

$\mathrm{K}_{\mathrm{t}}=$ thermal conductivity of the tube

$\mathrm{C}_{\mathrm{b}}=$ bond conductance $(=\mathrm{Kb} \mathrm{b} / \mathrm{t})$

$\mathrm{Kb}=$ bond material thermal conductivity

$\mathrm{b}=$ bond width

$\mathrm{t}=$ bond thickness

$\mathrm{mt}=$ tube thickness

$\mathrm{F}=$ fin efficiency factor given as:

$$
\mathrm{F}=\frac{\tanh [\mathrm{a}(\mathrm{W}-\mathrm{D}) / 2]}{\mathrm{a}(\mathrm{W}-\mathrm{D}) / 2}
$$

Efficiency of solar cell:

$$
\eta=\frac{\text { incident radiation }}{\text { power radiation }}
$$

Typical standard test condition for efficiency measurement 
Irradiance $1000 \mathrm{w} / \mathrm{m} 2$ or $800 \mathrm{w} / \mathrm{m} 2$

\subsection{Effect of mass flow rate on the PVT collectors}

The mass flow rate through the collectors and into the designated channels indirectly affects PV module cooling. The effects of the mass flow rate on the absorber collectors are shown in Figs. 9-11. The mass flow rates used in this analysis $(0.011-0.041 \mathrm{~kg} / \mathrm{s})$ were later applied under various solar radiation levels. The results show that increasing the mass flow rate simultaneously decreased the PV temperature of the PVT collectors at all solar radiation levels. At the same mass flow rate, the PV temperatures in-creased in the solar radiation level. Figs. 5-9 show that from $0.011 \mathrm{~kg} / \mathrm{s}$ to $0.041 \mathrm{~kg} / \mathrm{s}$ mass flow rates and under $500 \mathrm{~W} / \mathrm{m} 2$ solar

Fig4.2.2. Changes in PV efficiency with the mean PV temperature of the PVT absorber collectors under 600 $\mathrm{W} / \mathrm{m} 2$ of solar radiation.

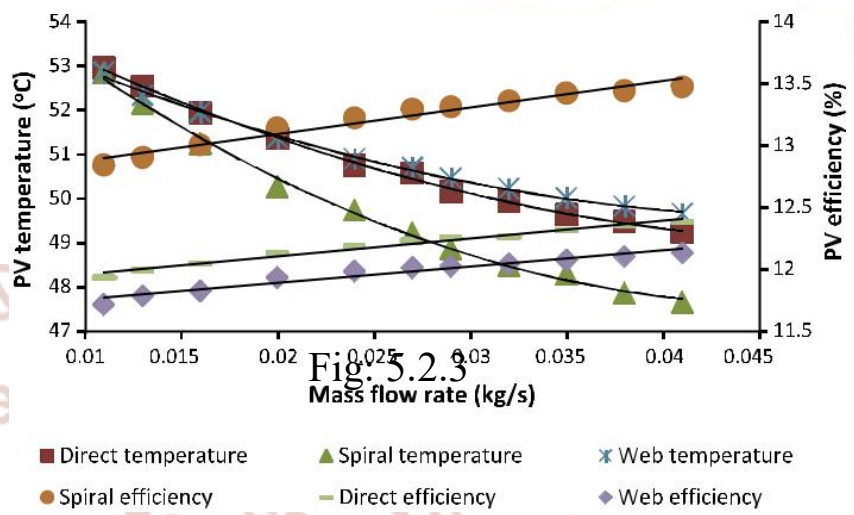

Fig: 4.2.4 Changes in PV efficiency with the mean PV temperature of the PVT absorber collectors under 700 $\mathrm{W} / \mathrm{m} 2$ of solar radiation.

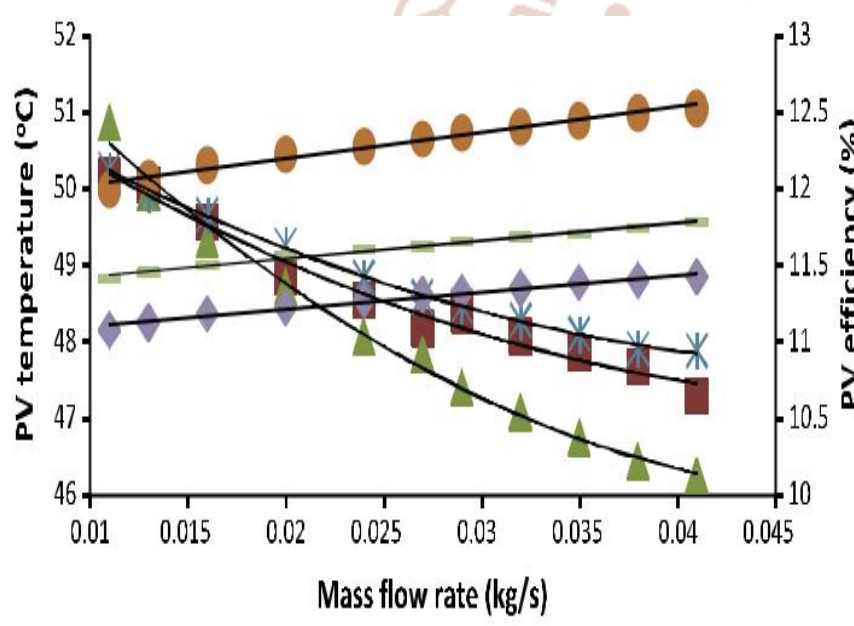

Direct temperature - Spiral efficiency

$\triangle$ Spiral temperature

* Web temperature = Direct efficiency

$\checkmark$ Web efficiency

Fig. 4.2.1. Changes in PV efficiency with the mean PV temperature of the PVT absorber collectors under $500 \mathrm{~W} / \mathrm{m} 2$ of solar radiation.

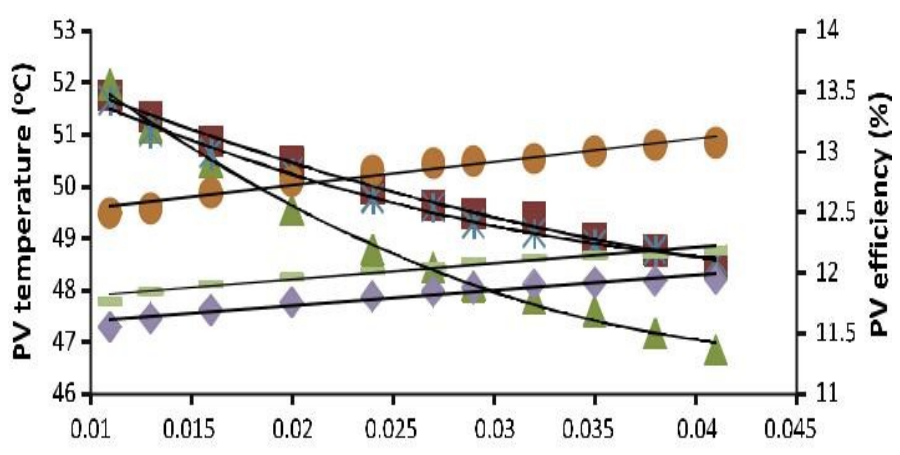

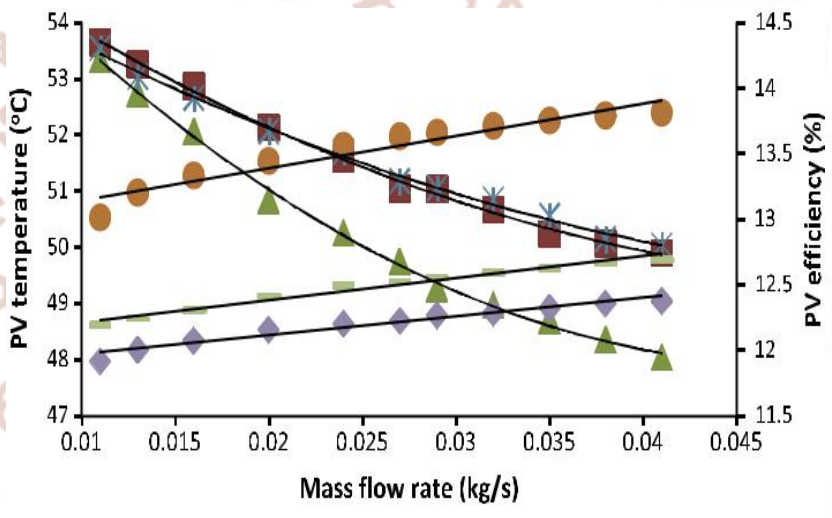

Direct temperature $\quad \Delta$ Spiral temperature $\quad *$ Web temperature - Spiral efficiency - Direct efficiency $\quad$ Web efficiency

Fig: 4.2 .5

Fig:4.2.5 Changes in PV efficiency with the mean PV temperature of the PVT absorber collectors under 800 $\mathrm{W} / \mathrm{m} 2$ of solar radiation.

The temperature decreased from $50.20 \mathrm{LC}$ to 47.76 LC and PV efficiency simultaneously increased from $11.07 \%$ to $11.42 \%$. When solar radiation was increased to $800 \mathrm{~W} / \mathrm{m} 2$, temperature dropped from 53.5 LC to $50 \mathrm{LC}$, whereas PV efficiency increased from $11.91 \%$ to $12.37 \%$. For the direct flow absorber as (Fig. 10) and referring to Figs. 5-8, at solar radiation of $500 \mathrm{~W} / \mathrm{m} 2$ and when mass flow rate increased from $0.011 \mathrm{~kg} / \mathrm{s}$ to $0.041 \mathrm{~kg} / \mathrm{s}$, PV temperature dropped from $50.11 \mathrm{LC}$ to $47.18 \mathrm{LC}$, and PV 
efficiency in-creased from $11.41 \%$ to $11.78 \%$. The same result was obtained when the solar radiation increased to $800 \mathrm{~W} / \mathrm{m} 2$ : temperature de-creased from 53.6 LC to $49.8 \mathrm{LC}$, whereas PV efficiency increased from $12.19 \%$ to $12.69 \%$.

\section{TABULATION}

Result of PV module and PV/T system Flow under various mass flow rates and solar radiations

Table : 5.2.3 Mechanical Energy

\begin{tabular}{|l|l|l|l|}
\hline Timing & $\begin{array}{l}\text { Mass flow } \\
\text { rate }\end{array}$ & T in & Tout \\
\hline 10 & 0.011 & 26 & 32 \\
\hline 11 & 0.013 & 26 & 38 \\
\hline 12 & 0.015 & 26 & 38 \\
\hline 1 & 0.016 & 27 & 39 \\
\hline 2 & 0.018 & 28 & 38 \\
\hline 3 & 0.017 & 28 & 38 \\
\hline 4 & 0.016 & 28 & 38 \\
\hline
\end{tabular}

Table : 5.2.3 Electrical Energy

\begin{tabular}{|l|l|l|l|l|}
\hline Timing & V 1 & I1 & Voc & Ioc \\
\hline 10 & 17 & 0.4 & 17 & 0.6 \\
\hline 11 & 16 & 0.3 & 18 & 0.7 \\
\hline 12 & 15 & 0.3 & 17 & 0.8 \\
\hline 1 & 16 & 0.4 & 17 & 0.8 \\
\hline 2 & 16 & 0.5 & 17 & 0.9 \\
\hline 3 & 7 & 0.6 & 18 & 0.7 \\
\hline
\end{tabular}

\section{CONCLUSION:}

The efficiency of photovoltaic panel is sensitive to operating temperature and decreases when the temperature of the PV increases. Therefore, the PV/T hybrid systems are one means used to improve the electrical efficiency of the panel. In the study, the photo voltaic panel temperature significantly reduced by $15-20 \%$ due to the flow of water through the manifold to the rear of the PV panel (recalling that it is about $60 \_\mathrm{C}$ to $80{ }_{-} \mathrm{C}$ in the conventional photovoltaic solar panel)

For all previously stated, we can say that our objective is to get a more effective exploitation of solar energy by the advantage materials and technical means used (galvanized steel, water) that reduce costs and required installation area, and of the part photovoltaic simply we get a better performance of the Collector. For which reason its use does not change, with the removal of the thermal energy produced What's used in various other applications exist (water heating, drying, air conditioning, etc.).

\section{REFERENCES}

1. Alibakhsh Kasaeiana \& Giti Nouria, Parisa (2018), Solar collectors and photovoltaic as combined heat and power systems:

2. Sobrina Sobria, \& Sam Koohi-Kamalia (2018) solar photovoltaic integration requires the capability of handling the uncertainty and fluctuations of power output.

3. Yunfeng Wang \& and Ming Li (2018) Experimental investigation of a solar-powered adsorption refrigeration system with the enhancing desorption

4. Xiao Jiao Yang, \& Liang Liang Sun (2017) the Experimental investigation on performance comparison of $\mathrm{PV} / \mathrm{T}-\mathrm{PCM}$ system and $\mathrm{PV} / \mathrm{T}$ system

5. Hasan Saygin \& Raheleh Nowzari (2017) Performance evaluation of a modified PV/T solar collector: A case study in design and analysis of experiment: Solar Energy 141 (2017) 210-221.

6. Pierre-Luc Paradis a \& Daniel R. Rousse a (2017) 2-D transient numerical heat transfer model of the solar absorber plate to improve $\mathrm{PV} / \mathrm{T}$ solar collector systems:

7. Arunkumar. G | Dr. P. Navaneetha Krishnan "Experimental Enhancement of Heat Transfer Analysis on Heat Pipe using $\mathrm{SiO} 2$ and TiO2 Nano Fluid" Published in International Journal of Trend in Scientific Research and Development (ijtsrd), ISSN: 2456-6470, Volume2 | Issue-4, June 2018

8. Gang Wang, Yaohua Zhao \& Zhenhua Quan, and Jiannan Tong (2017) Application of a multifunction solar-heat pump system in residential buildings: 